\title{
A New Pull-Out Technique for In-Place Estimation of Concrete Compressive Strength
}

\author{
F. Latte Bovio, ${ }^{1}$ G. Latte Bovio, ${ }^{1}$ A. Brencich, ${ }^{2}$ G. Cassini, ${ }^{2}$ D. Pera, ${ }^{2}$ and G. Riotto ${ }^{2}$ \\ ${ }^{1}$ BOVIAR SRL, via Rho 56, 20020 Lainate, Italy \\ ${ }^{2}$ Department of Civil, Chemical and Environmental Engineering, University of Genoa, Via Montallegro 1, 16145 Genova, Italy
}

Correspondence should be addressed to A. Brencich; brencich@dicca.unige.it

Received 27 May 2013; Revised 6 December 2013; Accepted 19 December 2013; Published 6 February 2014

Academic Editor: Jiangbo Sha

Copyright (C) 2014 F. Latte Bovio et al. This is an open access article distributed under the Creative Commons Attribution License, which permits unrestricted use, distribution, and reproduction in any medium, provided the original work is properly cited.

\begin{abstract}
A new type of postinstalled wedge anchor (B15G) is presented. A refined geometry of the anchor bolt and a careful choice of all the technical details allow the insert to work also in tensile stress states and to avoid much of the practical uncertainties that affect the commonly used procedures. The calibration of the procedure has been performed on 3 classes of concrete and for 5 stress distributions (medium and low compression, vanishing stress states, inhomogeneous compressive stresses, and inhomogeneous tensile stresses). It has been found that the correlation curves, pull-out force versus compressive strength, are not linear and depend on the stress state; besides, the statistical scattering of the calibration tests never exceeds $7-8 \%$ of the average values.
\end{abstract}

\section{Introduction}

The pull-out of pre- or postinstalled inserts (preferred, due to practical reasons) is, among the MDT tests, perhaps the most widely used technique to estimate the in situ compressive strength of concrete. It measures the force needed to pull out a metal insert (with enlarged head) embedded into concrete, deducing the material strength by means of experimental calibration curves related to the specific geometry of the insert.

The pulling force is applied to the insert by a hydraulic jack counterbalanced by a reaction ring, Figure 1, so that the insert extracts a concrete cone whose dimensions depend on the geometry of the experimental setup. In this way, an Ultimate Limit State condition, with a mixed compressiveshear stress state, is obtained which makes this test be highly reliable $[1,2]$. Even though the original idea dates back to the end of the 30's-mid 40's [3,4], the modern pull-out test is due to the Danish works (Lok-strength test) in the ' $60 \mathrm{~s}$ and ' $70 \mathrm{~s}$ [5] and to the subsequent research in the USA $[1,6,7]$.

For preinstalled inserts, the collapse mechanism is represented in Figure 1. In the first stages of the load test, a tensile crack is initiated at the base of the insert (Figure 1(a)) but its propagation is stopped due to the activation of a compressed cone-shaped strut connecting the base of the insert to the reaction ring (Figure 1(b)). The collapse condition is activated close to the peak load in a mixed compressive-shear stress state that is responsible for a convex lateral surface of the cone (Figure 1(c)), that is, half of an hour glass [5].

Cast-in-place inserts, as represented in Figure 1, need to be placed in the formwork prior to concrete pouring, which asks for a rational design of the tests and specific attention to be paid when pouring concrete.

In the case of existing structures the insert is postinstalled and the technology is substantially that of a wedge anchor. Two technologies have been developed for postinstalled inserts: (i) split-sleeves coupled to a tapered bolt [8-11]; (ii) undercut drilling with expandable rings [12]. The first type tried either to reproduce the collapse mechanism of preinstalled inserts and to test some modification to the basic setup. The latter test, the CAPO-test, aims at reproducing an experimental setup as close as possible to the that of Figure 1. The recent research on postinstalled inserts showed a much higher error if compared to preinstalled inserts.

The technique used in western Europe, Figure 2, is a simplification of the CAPO-test that reproduces the setup and the collapse mechanism of Figure 1. The drilled hole is widened by means of a special drill bit, Figure 2(a), in order to obtain a kind of cone-type drill. The split sleeve is widened 


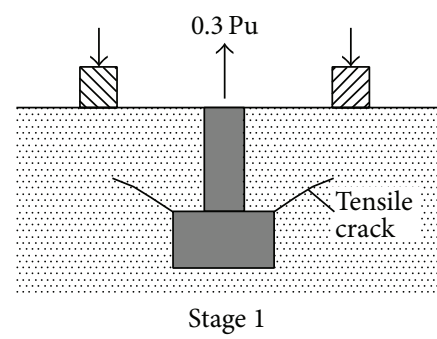

(a)

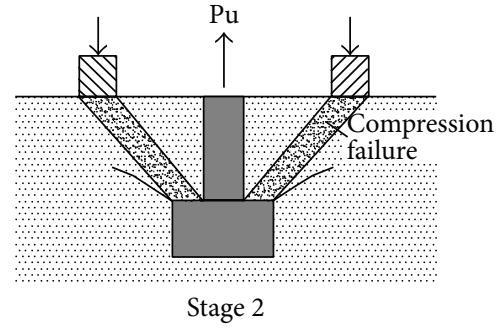

(b)

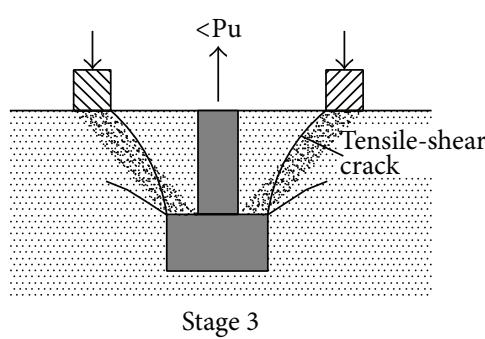

(c)

FIGURE 1: Failure mechanism of the pull-out test [1].

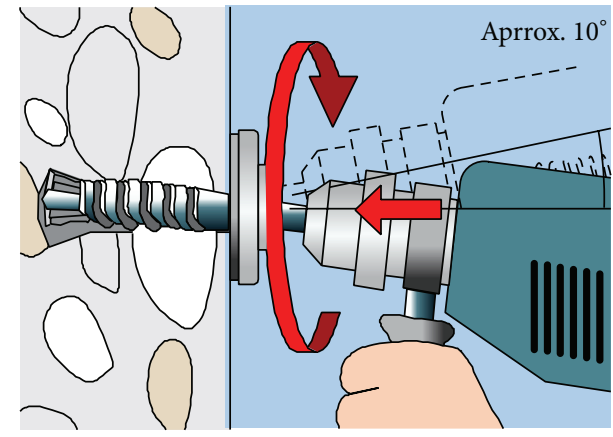

(a)

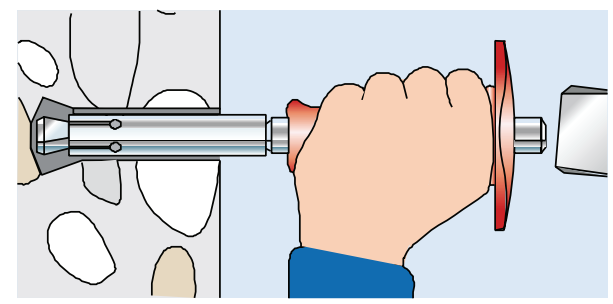

(b)

FIGURE 2: Standard European pull-out technology; (a) cone-shaped drill done by a swinging bit; (b) anchor bolt inserted and activated by manual hammering.

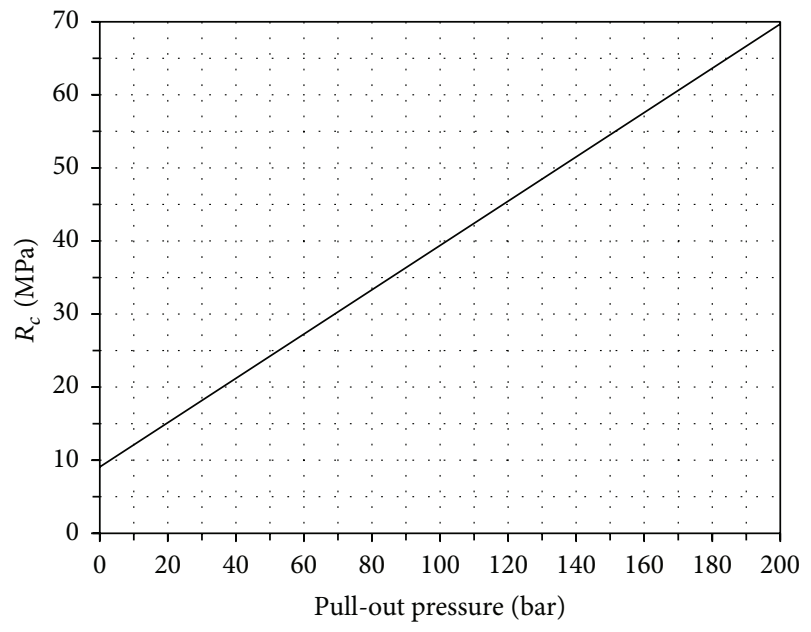

— Standard European pull-out

FIGURE 3: Standard correlation curve for the European pull-out test. $R_{c}=$ cubic compressive strength.

by means of a tapered bolts and manual hammering, Figure 2(b). The concrete compressive strength is deduced from the pull-out force by means of a unique linear correlation curve of uncertain origins, Figure 3.

In spite of its wide use, several issues still need a deeper insight: (i) postinstalled pull-out fails in tensile stress states; (ii) available correlation curves do not depend neither on
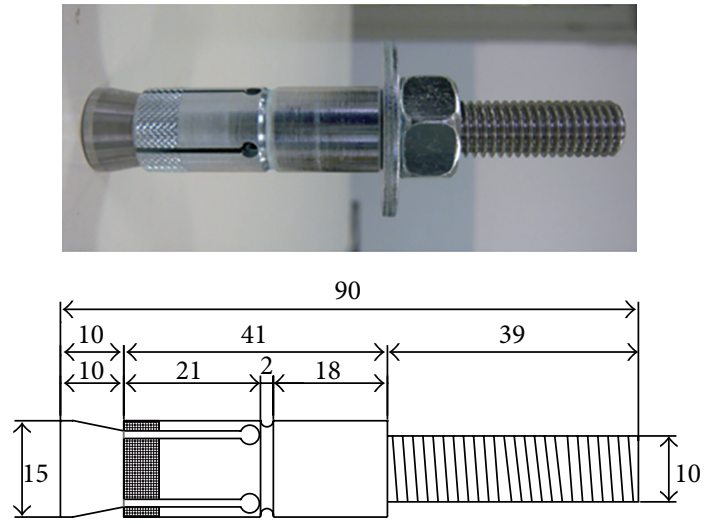

FIGURE 4: The new B15G split-sleeve.

the stress state nor on the value of the peak stresses; (iii) correlation curves are of uncertain origin and their reliability is unknown; (iv) technical procedures are affected by some uncontrolled technological issues.

In this paper a new split-sleeve and a new installing procedure are presented. The tests performed on a large number of samples, different either for concrete class and for stress state, show that the collapse mechanism is that of Figure 1, underline the rather good performance of the new system, and, last but not least, show that calibration of pull-out tests not taking into account the stress state might lead to severe 


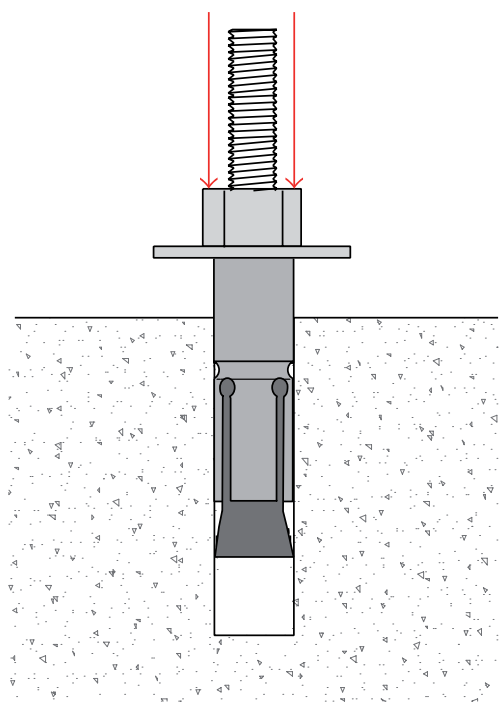

(a)

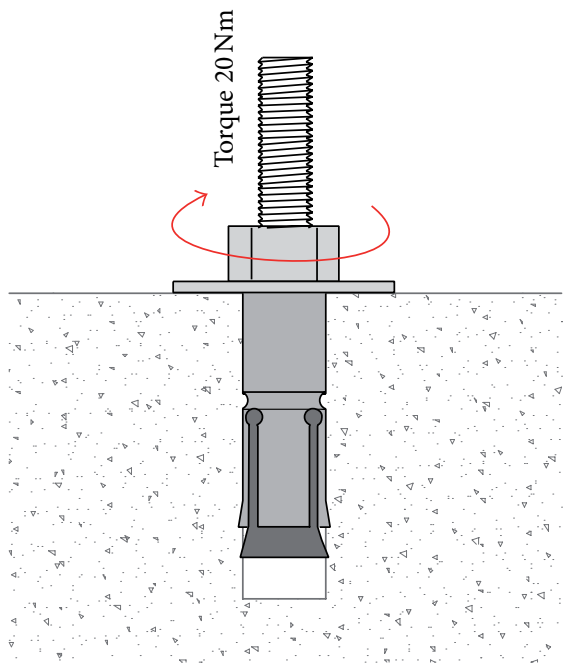

(b)

FIGURE 5: (a) Insertion of the split-sleeve by hammering the nut; (b) expansion by torque-controlled wrench.

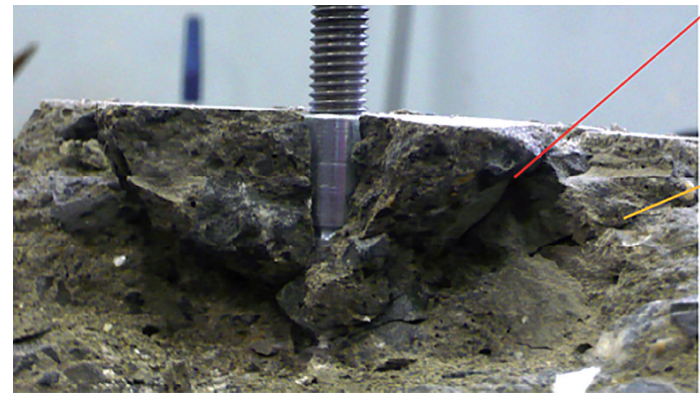

(a)

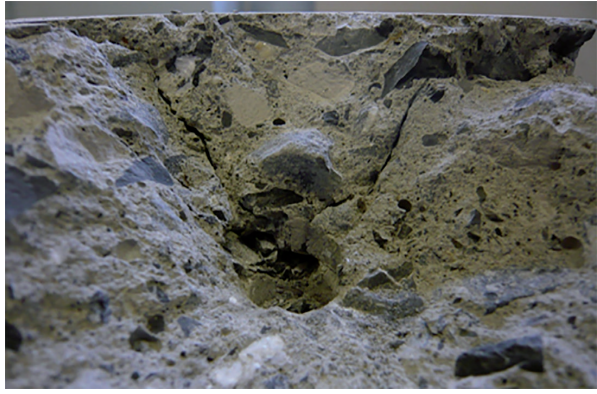

(b)

FIGURE 6: Concrete cone extracted by the B15G sleeve; (a) initial tensile crack of Figure 1(a) and fracture surface of Figure 1(c); (b) opposite side of the cracked specimen.

errors in the estimation of the concrete strength that may be as large as more than $50 \%$.

\section{The B15G Postinstalled Anchor}

The main drawbacks of the standard European technology are (i) the cone-shaped drill asks high manual skill for conic and symmetrical cones to be drilled; (ii) under tensile stress states the insert slips out; (iii) the calibration curve is of unknown origin, does not take into account different stress states, and its precision is not known.

Figure 4 shows the main geometrical data of the new split-sleeve that has been arranged so as to respect the geometric limits of ASTM-C900-06, BS-1881-207:1992, UNI EN 10157_1992, and UNI EN 12554_03_2005 [13-16]. The drilling and expansion procedure is represented in Figure 5. The drill is cylindrical, $52 \mathrm{~mm}$ long; the forced split of the sleeve is obtained by applying a $20 \mathrm{Nm}$ torque. In this way the effects of manskill are reduced, since the vertical drilling is obtained by means of a specific frame driving the drill and

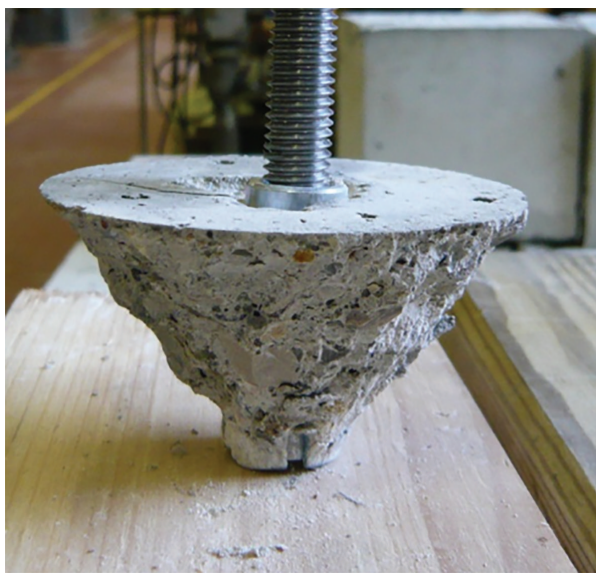

Figure 7: Extracted cone by the B15G sleeve.

no cone-shaped holes are needed. Besides, the expansion of the sleeve is controlled and not random as for the manual hammering of Figure 2. 


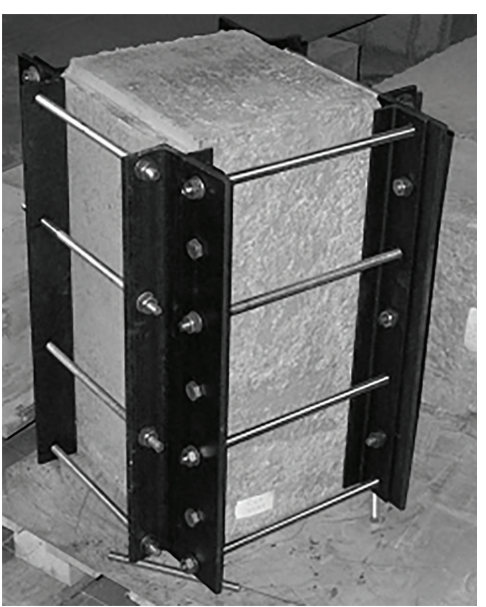

(a)

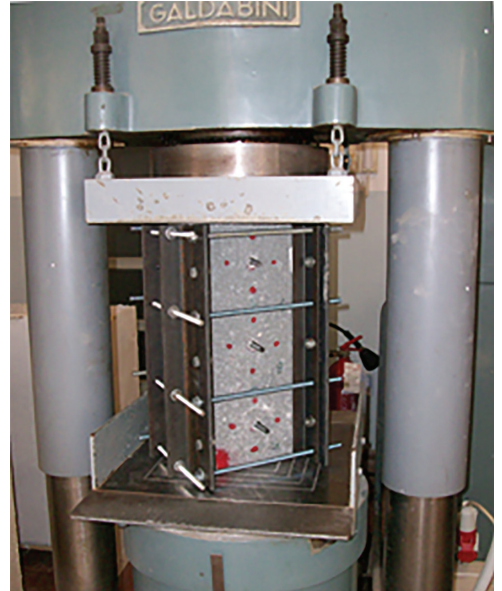

(b)

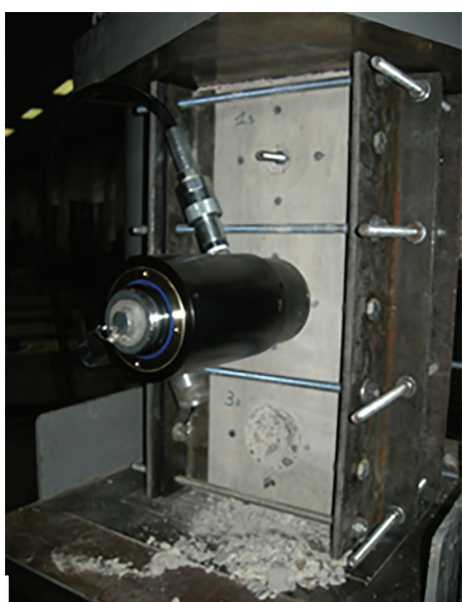

(c)

FIGURE 8: Testing setup for compressed prisms; (a) confining frame; (b) specimen in the press; (c) loaded specimen, extracting jack, anchor bolts ready for the test (up), and holes of the already performed tests (below).

Due to the geometry of the sleeve and of the tapered bolt the expansion of the bolt is large enough to fix the system not only in tensile stess states but also in highly fractured concrete.

Figures 6 and 7 show the cone extracted by the sleeve. The yellow line of Figure 6(a) shows the tensile crack developed during the sleeve expansion phase, similar to what is represented in Figure 1(a). The red line represents the fracture surface of the cone, also represented in Figure 6(b); the width of the concrete cone is $78-82^{\circ}$ on the average.

\section{Testing Campaign}

The calibration campaign used 3 different concrete classes (Bolomey curve), Table 1, and 5 different stress fields: $10 \mathrm{MPa}$ and $5 \mathrm{MPa}$ uniform compres-sion, Figure 8 , unloaded concrete, Figure 9, compression and traction with strong gradients, Figures 10, 11, and 12. For each calibration case (Table 2) 12 pull-out tests have been performed for a global number of 240 tests (further tests are being carried on).

Main data on the specimen are as follows:

(i) compressed prisms: $25 \times 25 \times 55 \mathrm{~cm}$,

(ii) unloaded concrete: $40 \times 80 \times 120 \mathrm{~cm}$,

(iii) slabs: $120 \times 600 \times 15 \mathrm{~cm}, M_{s}=0.90 M_{r}$; at midspan the intrados show clear cracking. Neutral axis is $3 \mathrm{~cm}$ from the extrados.

Further details are as follows:

(i) since the expansion of the sleeve induces transversal traction in concrete, the compressed prisms had to be confined by means of devices (not prestressed) reproducing the effect of stirrups in r.c. columns, Figure 8;

(ii) the compression levels (5 and $10 \mathrm{MPa}$ ) are representative of average r.c. columns of ordinary structures.

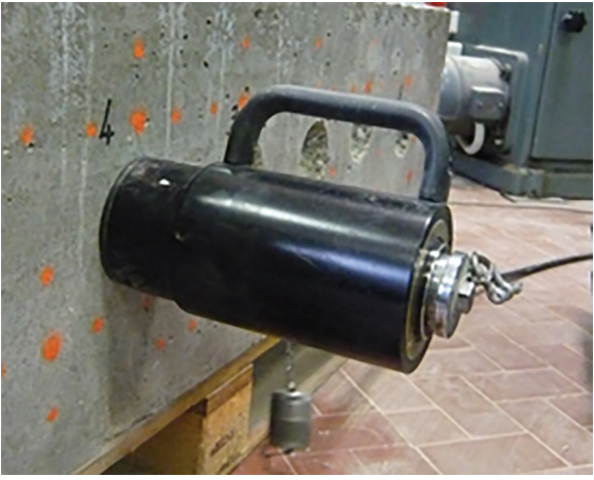

Figure 9: Pull-out of unloaded concrete.

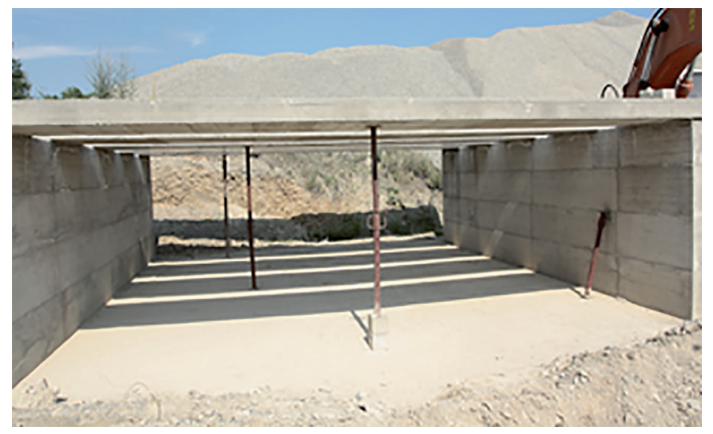

Figure 10: Solid r.c. slabs for testing stress fields with strong gradients.

Main data of pull out tests are as follows:

(i) pull-out tests duration: $55 \mathrm{sec}$ (av.);

(ii) fastening: $20 \mathrm{Nm}$ torque $\Rightarrow 1.15-2$ rotations;

(iii) loading rate: $1.4 \mathrm{kN} / \mathrm{sec}$;

(iv) displacement of the jack at pullout: $12 \mathrm{~mm}$ (av.);

(v) pressure gauge: class 0.1 . 
TABLE 1: Main data of the concrete classes.

\begin{tabular}{lccc}
\hline Class & C8/R10 & C25/R30 & C30/R37 \\
\hline$R_{c}$-cubic & $\mathbf{1 7 . 6}$ & 41.1 & 48.1 \\
$R_{c}$-std. dev. & 0.3 & 1.5 & 3.0 \\
$R_{c}$-CoV\% & 1.6 & 3.5 & 6.3 \\
Density $\left[\mathrm{kN} / \mathrm{m}^{3}\right]$ & 2133 & 2172 & 2180 \\
$f_{c}$-cylindrical & 15.5 & 34.7 & 40.0 \\
$f_{c}$-std. dev. & 1.3 & 1.9 & 2.4 \\
$f_{c}$-CoV\% & 8.7 & 5.6 & 6.0 \\
Density $\left[\mathrm{kN} / \mathrm{m}^{3}\right]$ & 2150 & 2179 & 2171 \\
$f_{c} / R_{c}$ & 0.88 & 0.85 & 0.84 \\
\hline
\end{tabular}

Legenda.

$R_{c}$ : cubic compr. strength.

$f_{c}$ : cylindrical compressive strength.

CoV: coefficient of variation $=$ std. dev./average value $* 100$.

TABLE 2: Stress states considered in the testing campaign.

\begin{tabular}{|c|c|c|c|}
\hline & Stress field & & \\
\hline 1 & $\begin{array}{c}\text { Inhomogeneous } \\
\text { Tensile }\end{array}$ & $\leftarrow$ & $\stackrel{\longrightarrow}{\longrightarrow}$ \\
\hline 2 & $\begin{array}{c}\text { Inhomogeneous } \\
\text { Compr. }\end{array}$ & & $\underset{\rightarrow}{\longrightarrow}$ \\
\hline 3 & Vanishing & & \\
\hline 4 & $\begin{array}{l}\text { Homogeneous } \\
\text { Compr. } 5 \mathrm{MPa}\end{array}$ & & \\
\hline 5 & $\begin{array}{l}\text { Homogeneous } \\
\text { Compr. } 10 \mathrm{MPa}\end{array}$ & 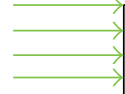 & \\
\hline
\end{tabular}

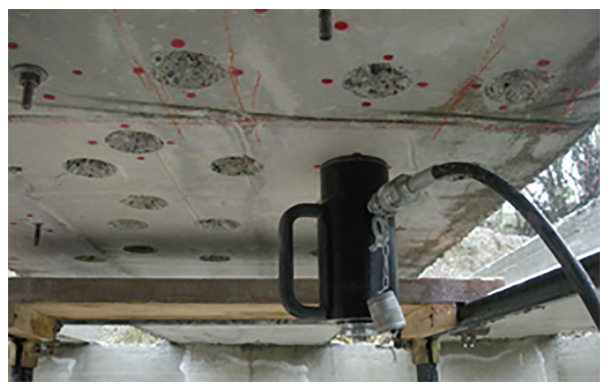

(a)

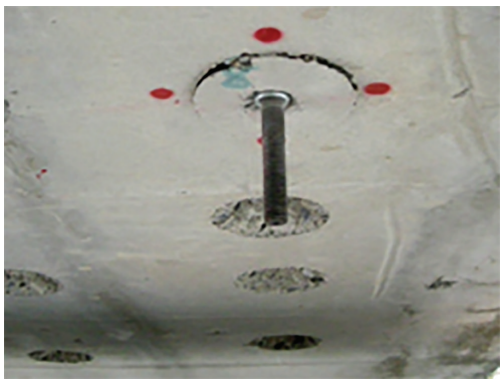

(b)

Figure 11: Pull-out in tensile stress states (intrados of the slab of Figure 10); (a) general view of the intrados; (b) detailed view of the extracted cone. 


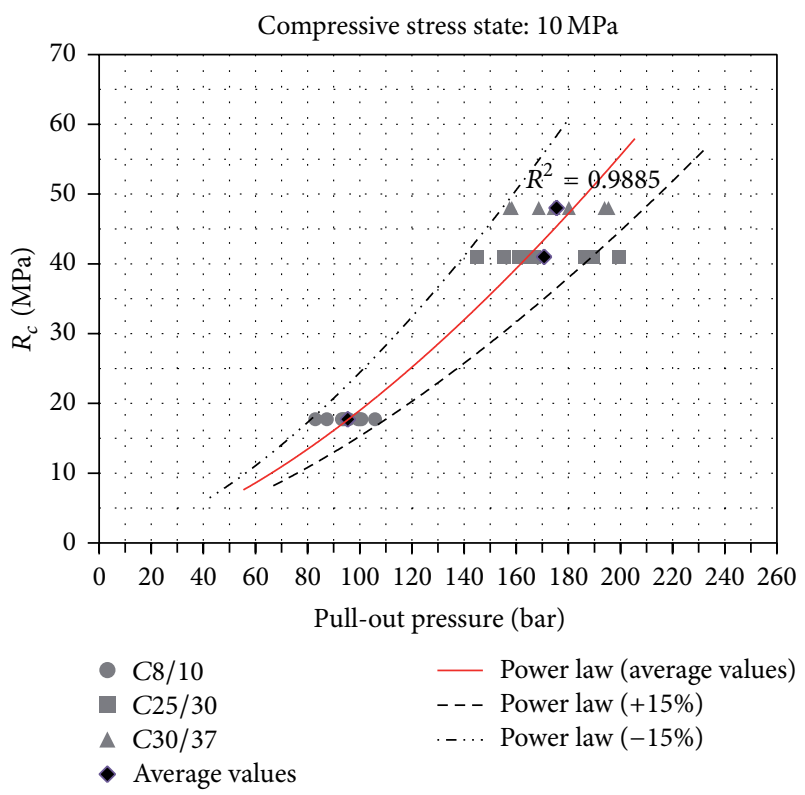

FIGURE 12: Calibration curve for $10 \mathrm{MPa}$ uniform compression stress.

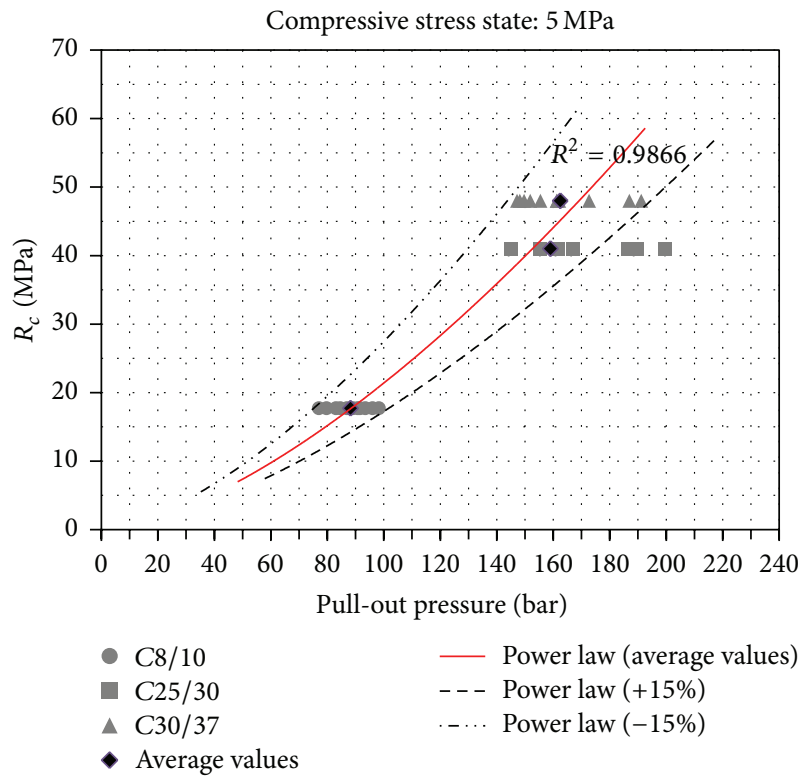

Figure 13: Calibration curve for $5 \mathrm{MPa}$ uniform compression stress.

\section{Calibration of the Procedure and Discussion}

Figures 12, 13, 14, 15, and 16 show the calibration curves and the experimental points. Figure 17 shows the comparison between the different curves along with the standard curve of Figure 3 (black line).

Some circumstances arise the following:

(i) the scattering of the data is rather low in the range $\pm 8 \%$ of the average value;

(ii) all the calibration curves, according to a best fitting procedure, are of a power-law type and not straight

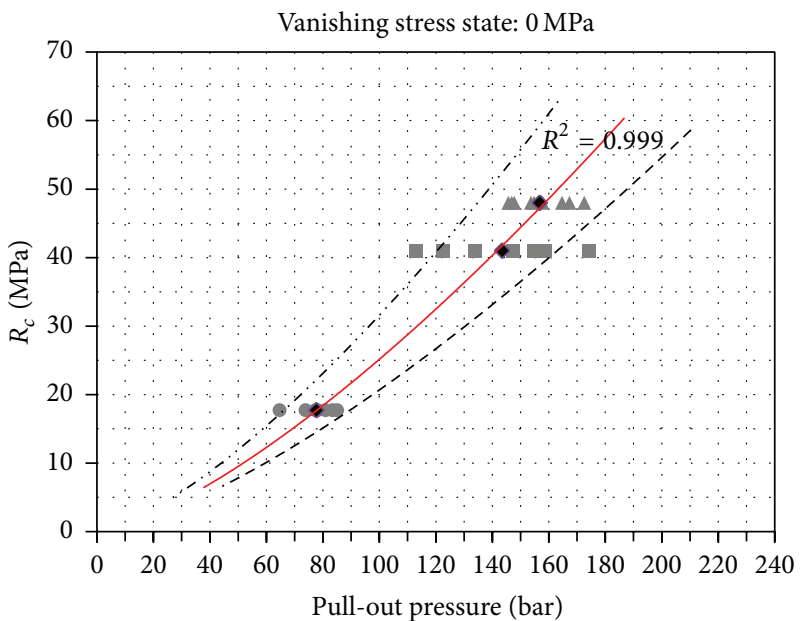

- $C 8 / 10 \quad$ Power law (average values)

- C25/30 - - Power law $(+15 \%)$

\ C30/37 - - - P Power law $(-15 \%)$

- Average values

FIgURE 14: Calibration curve for vanishing stress.

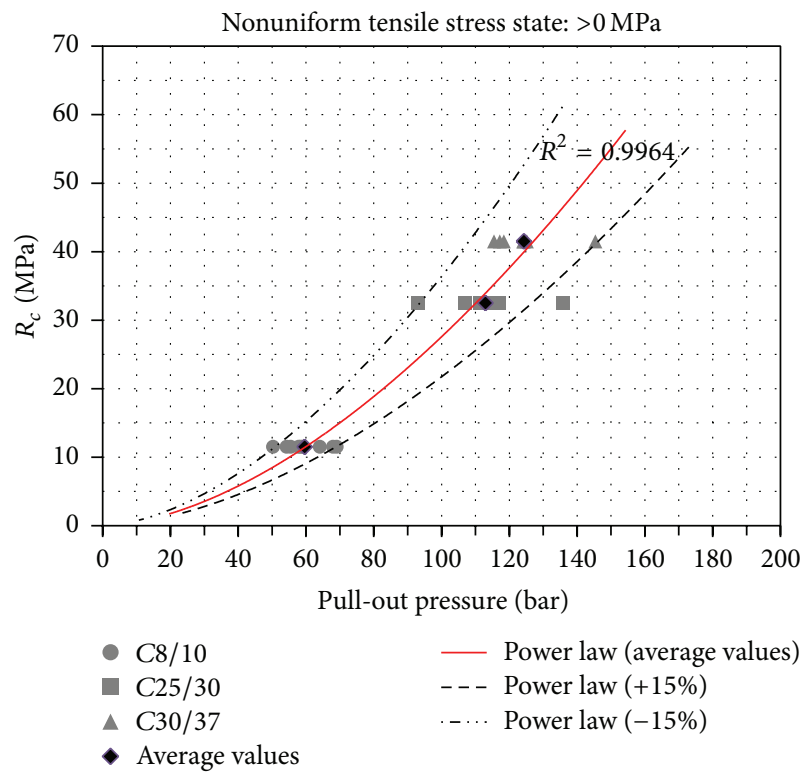

FIGURE 15: Calibration curve for nonuniform tensile stress.

as commonly used. This can be explained considering that the ratio tensile strength/compressive strength of concrete increases as the concrete class increases;

(iii) the stress state that is usually neglected in calibration curves [1] is not a secondary issue and, if neglected, enlarges the error from 2 to 5 times;

(iv) the standard curve is generally above the calibration curves obtained in this work, overestimating the concrete strength that may be as large as $150 \%$ for low strength concretes.

This latter outcome is not unexpected: since the stress state on the fracture surface is a mixed traction-shear distribution, 


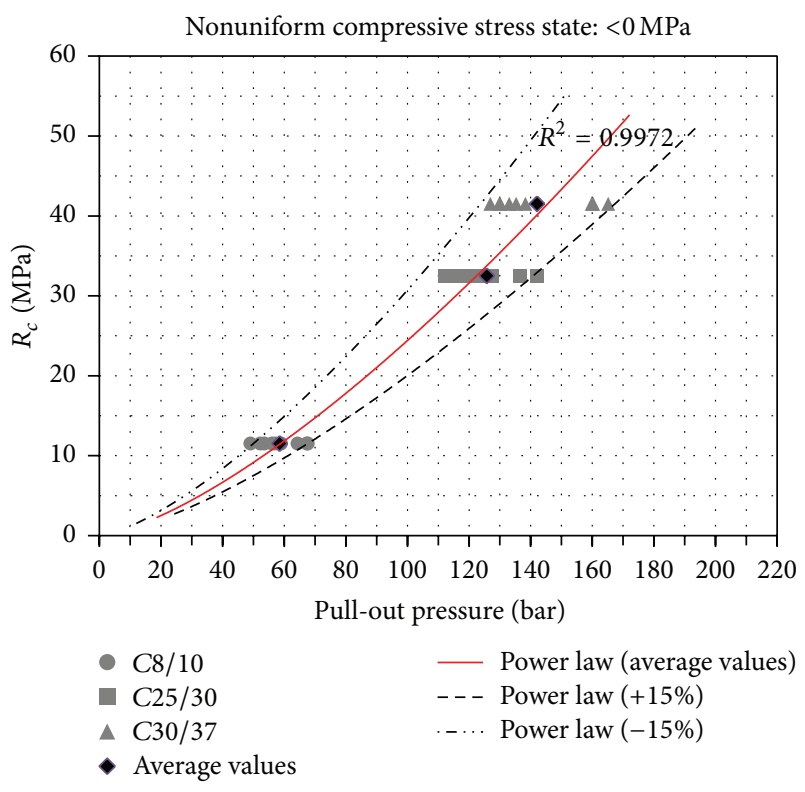

FIgURE 16: Calibration curve for nonuniform compression stress.

transversal compressive stresses activate frictional mechanisms that increase the pull-out force. On the contrary, tensile stresses reduce frictional mechanisms and the interlocking across the fracture surface due to the aggregates and, at the same time, increase the tensile component of the tensile stress field.

\section{Conclusion}

The new geometry of the splitting-sleeve for postinstalled inserts allows a relevant improvement of the standard commercial technique because of the following:

(i) it allows pull out tests to be used also in tensile stress states (not a failure in the whole testing campaign);

(ii) the data scattering is unexpectedly low, showing a reduced error of the new technology;

(iii) the improved precision is due to a high-level production technology of the sleeve and to a drilling phase that is almost independent on the man skill;

(iv) calibration curves for different stress states allow a good precision also when specific calibration on the specific concrete is not possible.

The test data on concrete suggest that the cylindrical/ cubic strength of concrete is not constant, decreasing as concrete class increases.

Further work is being carried on both the calibration of the B15G sleeve, working on high strength concrete (till $75 \mathrm{MPa}$ ), and the cylindrical/cubic strength ratio.

\section{Conflict of Interests}

The authors declare that there is no conflict of interests regarding the publication of this paper.

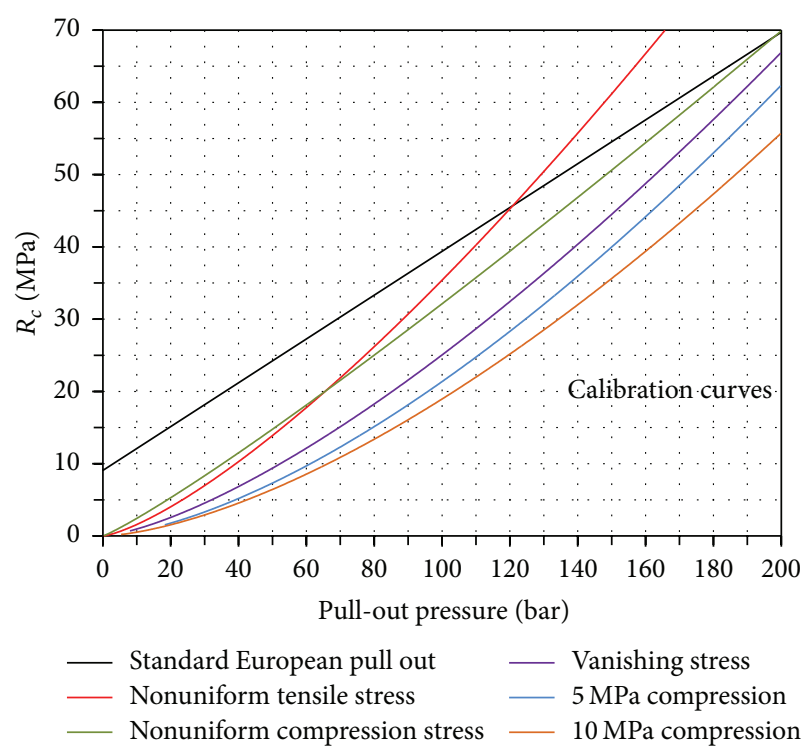

FIGURE 17: Comparison of the calibration curves.

\section{Acknowledgments}

This research is an industrial partnership between BOVIAR and the Structural Engineering Laboratory of the DICCA, Department of Civil, Chemical and Environmental Engineering of the University of Genoa, which fully funded the research program. Calcestruzzi Farina gave fundamental and completely unselfish contribution producing all the concrete specimen. This is quite rare and deserves specific mention.

\section{References}

[1] V. M. Malhotra and N. J. Carino, Handbook on NonDestructive Testing of Concrete, CRC Press, Boca Raton, Fla, USA, 2nd edition, 2004.

[2] H. Krenchel and J. A. Bickley, "Pullout testing of concrete: historical background and scientific level today," Nordic Concrete Research, no. 6, pp. 155-168, 1987.

[3] B. G. Skramtajew, "Determining concrete strength for control of concrete in structures," Journal of the American Concrete Institute, vol. 34, pp. 285-303, 1938.

[4] B. Tremper, "The measurement of concrete strength by embedded pull-out bars," Proceedings-American Society for Testing and Materials, vol. 44, p. 880, 1944.

[5] P. Kierkegaard-Hansen, "Lok-strength," Nord Betong, vol. 3, p. 19, 1975.

[6] O. Richards, "Pullout strength of concrete," Reproducibility and Accuracy of Mechanical Tests, ASTM SP 626, 1977.

[7] M. Yener and W. F. Chen, "On in-place strength of concrete and pullout tests," Cement, Concrete and Aggregates, vol. 6, no. 2, pp. 96-99, 1984.

[8] A. J. Chabowski and D. Bryden-Smith, "A simple pull-out test to assess the strength of in-situ concrete," Precast Concr, vol. 8, no. 5, pp. 243-258, 1977.

[9] A. J. Chabowski and D. W. Bryden-Smith, "Assessing the strength of concrete of in-situ Portland cement concrete by 
internal fracture tests," Magazine of Concrete Research, vol. 32, no. 112, pp. 164-172, 1980.

[10] G. Mailhot, A. Bisaillon, G. G. Carette, and V. M. Malhotra, "Inplace concrete strength: new pull out methods," Journal of the American Concrete Institute, vol. 76, no. 12, pp. 1267-1282, 1979.

[11] P. L. Domone and P. F. Castro, "An expanding sleeve test for insitu concrete and mortar strength evaluation," in Proceedings of the Structural Faults and Repairs, vol. 87, Engineering Technics Press, Edinburgh, UK, 1987.

[12] C. G. Peterson, "LOK-test and CAPO-test development and their applications," ICE Proceedings, vol. 76, no. 2, pp. 539-549, 1984.

[13] "Standard test method for Pullout Strength of Hardened Concrete," ASTM C900-06.

[14] "Testing concrete. Part 207: recommendations for the assessment for concrete strength by near-to-surface tests," BS-1881207, 1992.

[15] "Hardened concrete: determination of the pull out force by means of post-installed forced split-sleeve inserts," UNI EN, 10157, 1992 (Italian).

[16] "Tests on concrete in structures. Part 3: determination of the pull out force,” UNI EN, 12554_03, 2005 (Italian). 

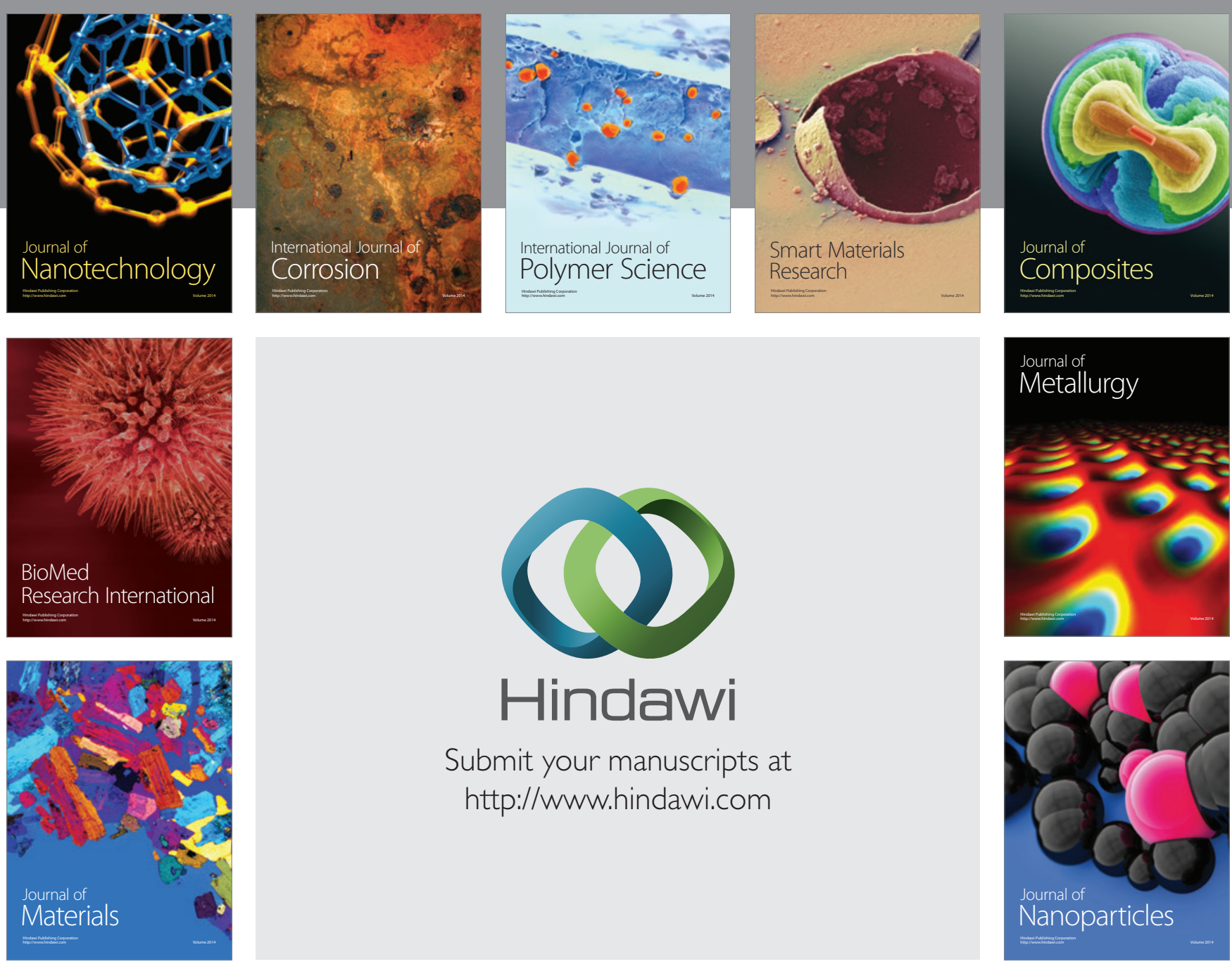

Submit your manuscripts at http://www.hindawi.com
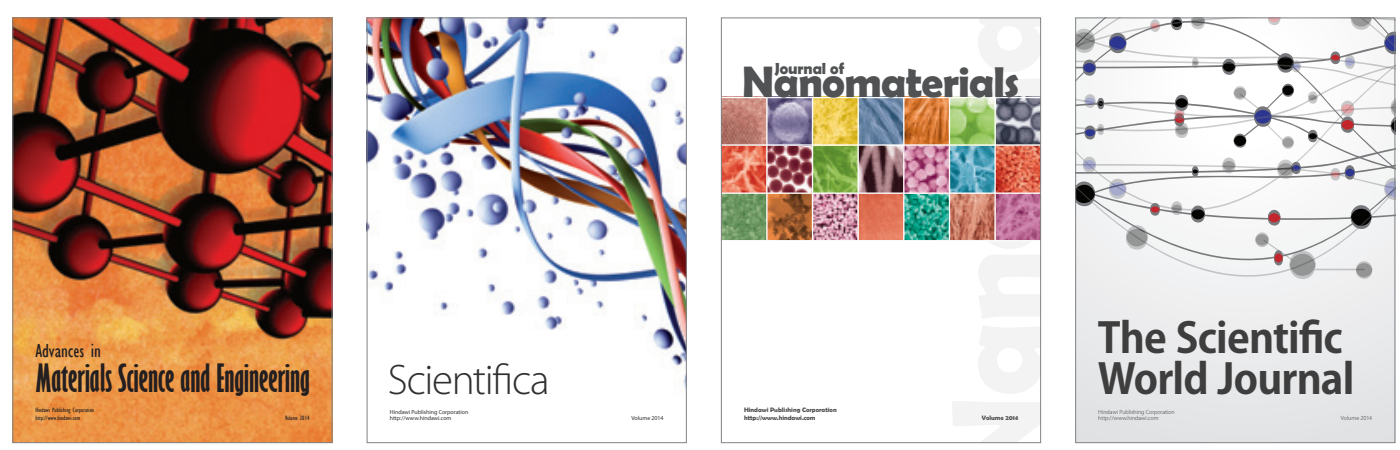

\section{The Scientific World Journal}
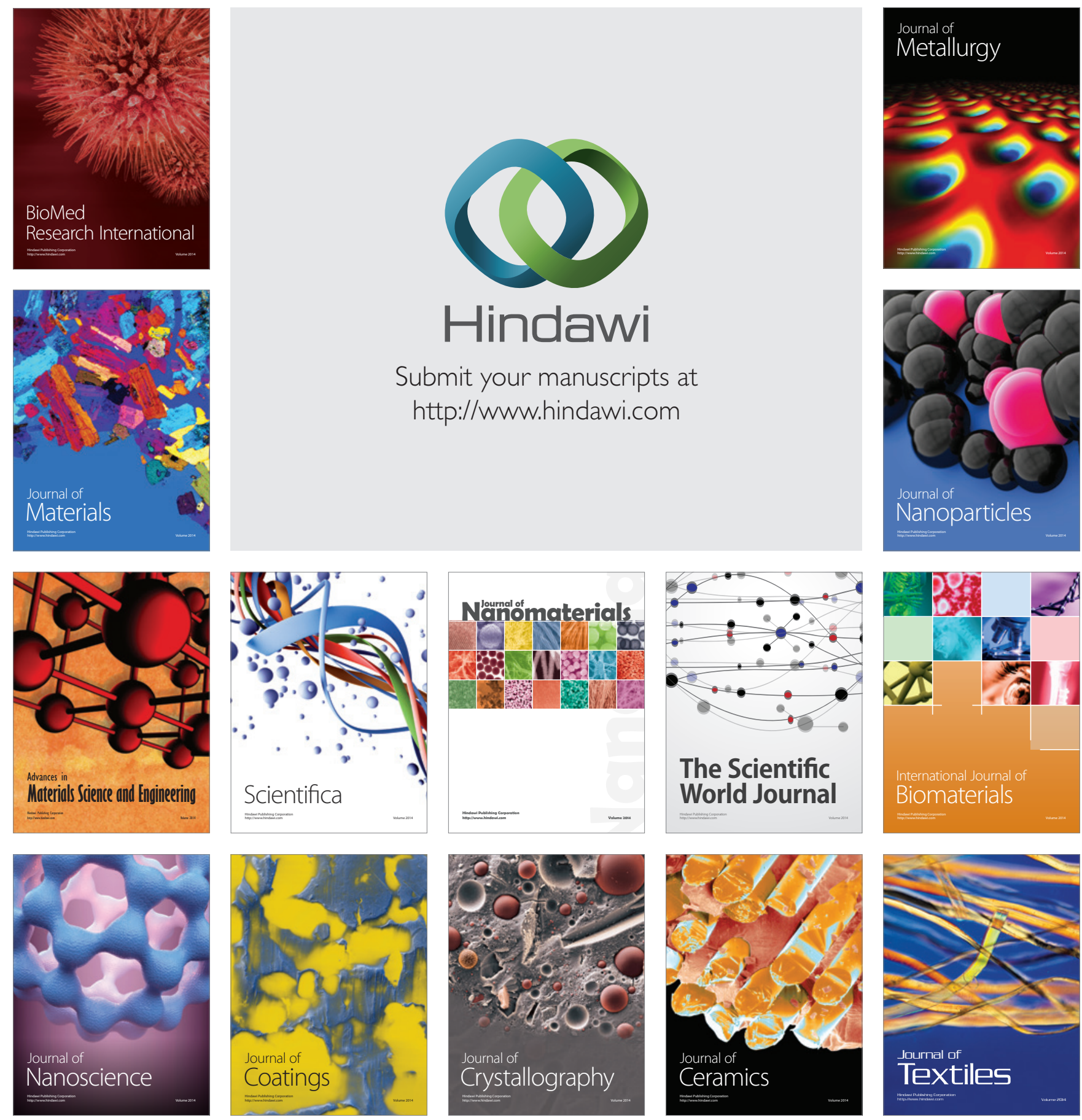